\title{
The Effect of Abusive Supervision on Budget Slack: The Mediating Role of Emotional Exhaustion
}

\author{
Ying Tong*, Manoch Prompanyo \\ School of Management, Shinawatra University, Bangkok, Thailand \\ Email: *tongying325@126.com
}

How to cite this paper: Tong, Y., \& Prompanyo, M. (2021). The Effect of Abusive Supervision on Budget Slack: The Mediating Role of Emotional Exhaustion. Open Journal of Accounting, 10, 17-29. https://doi.org/10.4236/ojacct.2021.102003

Received: October 16, 2020

Accepted: March 9, 2021

Published: March 12, 2021

Copyright (อ 2021 by author(s) and Scientific Research Publishing Inc. This work is licensed under the Creative Commons Attribution International License (CC BY 4.0).

http://creativecommons.org/licenses/by/4.0/

\section{(c) (i) Open Access}

\begin{abstract}
Past research demonstrates that abuse supervision significantly impacts subordinates' psychological distress, attitudes, workplace deviant behaviors and performance and thus has strong implications for organization. Most scholars believe that budget slack will lead to waste of resources and inefficient enterprises. How to restrain budget slack has always been one of the focus problems in budget practice and research. However, abuse supervision has not been explored in a budgeting context. Accordingly, we introduce the abusive supervision into the budget context and complement other negative behavior induced by abusive supervision to explore the influence path of abusive supervision on budget slack. Our results imply that the abusive supervision has a positive impact on budget slack of subordinate. In addition, emotional exhaustion played a fully mediating effect between abusive supervision and budget slack.
\end{abstract}

\section{Keywords}

Abusive Supervision, Budget Slack, Emotional Exhaustion

\section{Introduction}

As a kind of negative leadership behavior, abusive supervision exists in all kinds of organizations around the world, and has many negative effects on subordinates' attitude and behavior (Harvey et al., 2007; Huang et al., 2017). Several studies focus on negative consequences of abusive supervision. For example, Tepper (2000) finds that when subordinates perceive superiors' abusive supervision, they usually reduce their emotional commitment to the organization, leading to workplace deviant behavior. Sun (2019) empirically demonstrates that the 
higher the abusive supervision perceived by subordinates is, the higher the cheating behavior frequency. It further illustrates there is a significant positive effect between the abusive supervision and negative behavior of subordinates.

Budget is an important part of enterprise management and control system. Most enterprises have realized budget management in China (Yu et al., 2004). However, opportunistic behaviors such as budget slack are hidden in budget practice (Mao \& Zhu, 2009). Budget slack is the behavior in which budget actors deliberately underestimate actual income or capacity, or overestimate the cost or resources needed (Dunk \& Nouri, 1998). Most scholars believe that budget slack will lead to waste of resources and inefficient enterprises, thereby eroding enterprise value. It should be controlled (Dunk \& Nouri, 1998; Zhang \& Zhai, 2009). Therefore, how to restrain budget slack has always been one of the focus problems in budget research.

In the present research on budget slack, psychology-based researchers focus on employees' mental states and behavior, and propose that the emergence of individual budget slack behavior follows the chain of "stimulating - psychology behavior" (Covaleski et al., 2003), and in the process, the internal and external pressure felt by individuals is the most commonly used explanatory variable in the study (Libby, 1999; Webb, 2002; Stevens, 2002; Little et al., 2002). Besides, research demonstrates that the abusive supervision carried out by superiors is a main pressure source of subordinates (Ma et al., 2017). However, to our knowledge, the environment where abusive supervision remains unexplored is in a budgeting context.

In particular, psychology-based researchers from the protection motivation theory proposed that external stimulus (such as stress) can induce individuals to open up self-protection mechanism and then produce corresponding self-protection behavior (Rogers, 1975). Studies following this path examine the mediating effect of emotional exhaustion on the relationship between abusive supervision and negative behavior (Chi \& Liang, 2013; Whitman et al., 2012). To add to this literature, we draw from the protection motivation theory and research in budgeting to introduce the abusive supervision into budget context and explore the mediating effect of emotional exhaustion between abusive supervision and budget slack.

Our results provide several contributions to research and practice. First, this paper introduces the abusive supervision into the budget context and complements other negative behavior induced by abusive supervision to explore the influence path of abusive supervision on budget slack. Further, from the protection motivation theory, our results indicate empirical evidence on emotional exhaustion as a mediating link between abusive supervision and budget slack. Sum up, from the protection motivation theory in psychology, this paper discusses the effect of abusive supervision on budget slack and explores the mechanism of restraining budget slack from a deeper level.

The next section discusses the relevant literature and theoretical foundation to 
develop the hypotheses, and then, proposes the research method and results analysis. In the final section, it concerns about main concludes, innovations and further research prospects in the future.

\section{Development of Hypotheses}

\section{Abusive supervision and budget slack}

Scholars have reached a consensus on the positive correlation between information asymmetry and budget slack (Bourageois, 1981; Kren, 1992), and the information asymmetry between the superior and the subordinate is the prerequisite for the tendency of budget slack (Zhang et al., 2004).

Abusive supervision as a destructive negative leadership style has received widespread attention. The pressure on subordinates in their work is the main cause of negative behavior (Mitchell, Baer, Ambrose, Folger, \& Palmer, 2018), and the abusive supervision carried out by superiors is a main source of this pressure (Ma, Xi, Xu, \& Zhao, 2017). When subordinates are in a negative emotion for a long time, they gradually reduce the consideration of ethics and morality, and easily induce unethical behavior (Kouchaki \& Desai, 2015). The threat of abusive supervision can also lead to employees' cheating behavior (Sun, 2019). Moreover, the essence of budget slack is a moral adverse selection (Kren, 1992; Gao \& Peng, 2009). Follow this logic, in this paper, the process of abusive supervision positively affects the cheating behavior of subordinates is brought into the budget management environment. It is believed that abusive supervision will lead to budget slack.

Thus, the following hypothesis is tested:

$\mathrm{H}_{1}$ : The abusive supervision has a positively impact on budget slack of subordinate.

\section{Abusive supervision and emotional exhaustion}

Several studies in the psychology literature have shown that abusive supervision affects subordinates' work attitude and mental health, including emotional exhaustion, turnover tendency, work-family conflict, job satisfaction, organizational commitment, etc. (Ashforth, 1997; Tepper, 2000, 2007; Tepper, Duffy, Hoobler, \& Ensley, 2001). When employees feel threatened, they create psychological stress, which in turn produces a series of depleted states such as emotional exhaustion (Hobfoll, Freedy, Lane, \& Geller, 1990). As a stress, abusive supervision damages the psychological and physiological resources (Whitman et al., 2012) of employees. And studies have confirmed abusive supervision significantly stimulate emotional exhaustion of employees, when employees are subjected to abusive behaviors, such as being ignored, not supported, accumulated some negative emotions, causing emotional exhaustion (Cao, Li, \& Zhan, 2015).

When subordinates are in the emotional exhaustion, in order to avoid being punished for the decrease of performance (Golparvar, 2015), it is easy for the subordinates to take false reports or exaggerate his work performance and lead 
to cheating behavior of subordinates (Chi \& Liang, 2013; Whitman et al., 2012; Mitchell et al., 2018). In addition, Lawrence and Michele (2017) examined that emotional exhaustion, as a negative emotional, can reduce employees' self-management ability and relax their high standards, which may lead to some unethical behavior. When subordinates are in the emotional exhaustion, in order to avoid being punished for the decrease of performance, it is easy for the subordinates to take false reports or exaggerate his work performance to avoid punishment (Golparvar, 2015). Kim, Hwang, \& Lee (2008) supported when the subordinates is in the emotional exhaustion, its self-control ability will decline, which will affect its control of instinctive impulse, and then leading to the cheating behavior. For example, when subordinates are in the emotional exhaustion, they will give up their commitment to honesty and prefer instant rewards (Mazar et al., 2008).

There is also evidence to support the expectation that emotional exhaustion represents an intervening variable in abusive supervision and budget slack. In order to expand the psychological and behavioral mechanism of employees, many studies have taken emotional exhaustion as a mediating variable between abusive supervision and employees' negative behavior. For example, Whitman et al. (2012) based on conservation of resources theory, found that abusive supervision is significantly negatively correlated with subordinates' feedback avoidance behavior, and the emotional exhaustion plays a mediating role in it. Chi and Liang (2013) also based on conservation of resources theory, found that abusive supervision and negative work behavior of subordinates is significantly positive correlation. Emotional exhaustion plays a moderating role, while cognitive revaluation and expression inhibition play a moderating role. We propose a moderating effect of abusive supervision on budget slack through emotional exhaustion.

Thus, the following hypothesis is tested:

$\mathrm{H}_{2}$ : The emotional exhaustion significantly mediates the relationship between superior abusive supervision and budget slack of subordinate.

\section{Research Method}

\subsection{Participants}

In the selection of samples, at the enterprise level, follow the two restrictions: 1) the enterprise is in the manufacturing industry. Because in China the larger manufacturing enterprises are the first to put into the budget management system, and at present, they are the most extensive and mature enterprises in budget management practice (Yu et al., 2004); 2) the scale of the enterprises is not less than staff of 100. Because the scale of the enterprises is too small budget system is too simple, the budget function is too limited (Libby \& Linsay, 2010).

On the basis of the limitation of the research enterprises, the population selected in this paper is the employee of the production department. Because from the point of view of management accounting, the production department is the 
most important department of enterprise budget control system, and it is directly related to enterprise performance (Subramaniam \& Mia, 2003).

An online survey gathered data regarding individuals': 1) abusive supervision, 2) emotional exhaustion, 3) budget slack, and 4) demographic data.

After questionnaire surveys, a total of 600 questionnaires were issued, and 510 were recovered, excluding invalid questionnaires in the statistics, among which 400 were valid, and the effective recovery rate was $78.43 \%$. In 400 research samples, the proportion of respondents with more than 5 years of industrial experience is too high, accounting for more than $60 \%$. From the enterprise point of view, state-owned enterprises were the main respondents, accounting for more than $60 \%$, and the total proportion of enterprises more than 500 people accounted for over $50 \%$.

The Liker's five-point scale is used for the measurement of variables abusive supervision, emotional exhaustion, and budget slack in this survey questionnaire. The question-asking technique of Liker's five-point scale is to design a way for the respondents to judge whether their attitude towards a concept is positive or negative according to the specific score (McDaniel and Gates, 2015). In the Liker's five-point scale, the scale ranging from 1 representing Totally disagree to 5 representing Totally agree. Additional demographic information is presented in Table 1.

\subsection{Measures}

\section{Abusive Supervision}

The abusive supervision is a kind of feeling perceived by subordinates. At present, the more mature measurement scale in academic research is the 15 -item

Table 1. Demographic statistics.

\begin{tabular}{|c|c|c|c|}
\hline \multicolumn{4}{|c|}{$\begin{array}{l}\text { Personal Information, and Percentage of Participants from Different Ownership } \\
\text { and Scale of Industries }\end{array}$} \\
\hline & & $\mathrm{n}$ & Percentage \\
\hline \multirow{2}{*}{ Gender } & Female & 222 & $56 \%$ \\
\hline & Male & 178 & $44 \%$ \\
\hline \multirow{5}{*}{ Tenure } & less than 1 years (does not include 1 years) & 32 & $8 \%$ \\
\hline & 1 - 3 years (excluding 3 years) & 61 & $15.3 \%$ \\
\hline & 3 - 5 years (excluding 5 years) & 52 & $13 \%$ \\
\hline & 5 - 10 years (excluding 10 years) & 130 & $32.5 \%$ \\
\hline & more than 10 years & 125 & $31.3 \%$ \\
\hline \multirow{2}{*}{ Ownership } & State-owned enterprises & 251 & $63 \%$ \\
\hline & Non-state enterprises & 149 & $37 \%$ \\
\hline \multirow{3}{*}{ Scale } & $100-500$ person & 148 & $37 \%$ \\
\hline & $500-1000$ person & 161 & $40.25 \%$ \\
\hline & more than 1000 person & 91 & $22.75 \%$ \\
\hline
\end{tabular}


scale developed by Tepper (2000). It has been widely used in prior abusive supervision by scholars and verified to good reliability (Aryee et al., 2008; Thau \& Mitchell, 2010; Zhang et al., 2014) was used. The 15-item of an abusive supervision measure are positive score. The higher the score is, the more the abusive supervision is perceived by subordinates.

\section{Emotional Exhaustion}

The Maslach Burnout Inventory (MBI) developed by Maslach et al. (1986) has been widely used effectively in prior burnout research. MBI contains three dimensions: 1) emotional exhaustion, 2) depersonalization, and 3) diminished personal accomplishment. Among them, emotional exhaustion is the core dimension of burnout, which refers to the negative psychological state (Maslach, Jackson, Leiter, Schaufeli, \& Schwab, 1986) in which individuals over-consumption of their own resources (interpersonal relationships, knowledge and skills, etc.) to produce exhaustion, which is mainly manifested in the loss of interest and enthusiasm for something and the inability to raise spirit, etc. The emotional exhaustion scales has considerable psychometric support (Zhang et al., 2014; Li \& Li, 2006), and has been used in previous mental state studies alone (Lawrence \& Michele, 2017). Therefore, we used a self-rated measure of emotional exhaustion in the MBI (Maslach et al., 1986). The 9-item scale of an emotional exhaustion measure are positive score. That is, the higher the score is, the higher the emotional exhaustion frequency.

\section{Budget Slack (Dependent Variable)}

Budget slack is the behavior in which the subordinates to take advantage of the asymmetry between superior and subordinate, deliberately overestimate expenditure, underestimate income, or undervalue performance for the sake of their own interests (Dunk \& Nouri, 1998; Yu et al., 2004). A four-item scale of the tendency of budget slack measure employed by Onsi (1973) and used effectively in prior budgeting research was used.

\section{Control Variable}

Previous studies have shown that the employee's tenure have an impact on his budget behavior and attitude through experience effects (Schatzberg \& Stevens, 2008), and the ownership and scale are related to the budget characteristics of the enterprise and then affect the employee's budget behavior (Onsi, 1973). Therefore, in this study, the employee's tenure, the ownership and the scale of the enterprise are selected as control variables to exclude their interference with the employees' budget slack.

The employees' tenure is measured by interval range, and the empirical analysis is carried out according to interval assignment " $1-5$ ". As far as the ownership of the enterprise is concerned, it is simplified into two categories: state-owned enterprises and non-state-owned enterprises as category variables, and $0-1$ variables are formed by virtualization. The enterprise scale is calculated by the suggestion of Kimberly (1976) and according to the research population and sample determined in this paper, that is manufacturing enterprises with no 
less than 100 people. Further according to the large scale, medium and small scale of Chinese manufacturing enterprises, mainly divided into three categories, and assignment " $1-3$ ".

\section{Analysis and Results}

Table 2 presents the min, max, means and standard deviations, and Table 3 shows the correlations of the variables. The results in Table 3 show that there is a significant positive correlation between abusive supervision and emotional exhaustion ( $\mathrm{r}=0.454, p<0.01$ ), there is a significant positive correlation between abusive supervision and budget slack $(\mathrm{r}=0.208, p<0.01)$; there is a significant positive correlation between emotional exhaustion and budget slack $(\mathrm{r}=0.375, p$ $<0.01)$; there is a negative correlation between moral identity and emotional exhaustion $(\mathrm{r}=-0.173, p<0.01)$. The correlation between these variables is consistent with the research hypothesis, which provides preliminary evidence for the verification of theoretical hypothesis.

Following Baron and Kenny's (1986) research, we estimated three regression equations to test the hypotheses. 1) Independent variables (abusive supervision) have a significant effect on dependent variables (budget slack); 2) Independent

Table 2. Sample description and statistical analysis results.

\begin{tabular}{ccccc}
\hline Variables & Min & Max & Mean & SD \\
\hline Tenure & 1.00 & 5.00 & 3.64 & 1.283 \\
Ownership & 0 & 1.00 & 0.63 & 0.483 \\
Scale & 1.00 & 3.00 & 1.85 & 0.760 \\
Abusive supervision & 1.13 & 5.00 & 3.34 & 0.849 \\
Emotional exhaustion & 1.00 & 5.00 & 3.27 & 0.907 \\
Budget slack & 1.00 & 5.00 & 3.20 & 0.836
\end{tabular}

$\mathrm{N}=400$.

Table 3. Correlation analysis of variables.

\begin{tabular}{ccccccc}
\hline & Gender & Tenure & Ownership & Scale $\begin{array}{c}\text { Abusive } \\
\text { supervision exhaustion }\end{array}$ slack \\
\hline Gender & 1 & & & & & \\
Tenure & -0.072 & 1 & & & & \\
Ownership & 0.006 & $0.117^{*}$ & 1 & & \\
Scale & -0.033 & 0.039 & 0.060 & 1 & 1 \\
Abusive supervision & 0.003 & -0.046 & -0.028 & $0.137^{* *}$ & 1 & \\
Emotional exhaustion & 0.067 & 0.058 & $0.113^{*}$ & $0.116^{*}$ & $0.454^{* *}$ & 1 \\
Budget slack & 0.015 & $0.265^{* *}$ & $0.179^{* *}$ & $0.192^{* *}$ & $0.208^{* *}$ & $0.375^{* *}$
\end{tabular}

*. The significance level of the mean difference was $0.05 ;{ }^{*}$. The significance level of the mean difference was $0.01 . \mathrm{N}=400$. 
variables (abusive supervision) have a significant effect on mediating variables (emotional exhaustion); 3) both the independent variable (abusive supervision) and the mediating variable (emotional exhaustion) have a significant effect on dependent variables (budget slack).

The results in Table 4 show that: in Equation (1), when Budget Slack is regressed on Abusive Supervision, the regression coefficient for Abusive Supervision is significant, indicating that Abusive Supervision has a significant effect on Budget Slack ( $\beta=0.203, p=0.000)$; in Equation (2), when Emotional Exhaustion is regressed on Abusive Supervision, the regression coefficient for Abusive Supervision is significant, indicating that Abusive Supervision has a significant impact on Emotional Exhaustion $(\beta=0.454, p=0.000)$; in Equation (3), when Budget Slack is regressed on both Emotional Exhaustion and Abusive Supervision, Emotional Exhaustion is the only variable that contributes significantly to this equation (for Emotional Exhaustion, $\beta=0.304, p=0.000$ ). More importantly, after adding the mediating variable, the relationship between Abusive Supervision and Budget Slack becomes statistically insignificant $(\beta=0.065, p=$ 0.193), which indicate that Emotional Exhaustion play a fully mediating effect between Abusive Supervision and Budget Slack. Figure 1 shows the results for the mediating effect of Emotional Exhaustion. Thus, there is strong support for $\mathrm{H}_{2}$.

Table 4. Tests for mediation effect-regression results.

\begin{tabular}{|c|c|c|c|c|}
\hline & \multicolumn{4}{|c|}{ Standardized Coefficient $\beta$} \\
\hline & & Equation (1) & Equation (2) & Equation (3) \\
\hline \multicolumn{5}{|l|}{ Control } \\
\hline Tenure & 0.242 & 0.251 & 0.064 & 0.232 \\
\hline Ownership & 0.140 & 0.146 & 0.115 & 0.111 \\
\hline Scale & 0.175 & 0.146 & 0.044 & 0.133 \\
\hline \multicolumn{5}{|l|}{ Predictor } \\
\hline Abusive supervision & & 0.203 & 0.454 & 0.065 \\
\hline \multicolumn{5}{|l|}{ Emotional exhaustion } \\
\hline \multicolumn{5}{|l|}{ Mediator } \\
\hline Emotional exhaustion & & & & 0.304 \\
\hline$\delta \mathrm{R}^{2}$ & & 0.040 & 0.202 & 0.112 \\
\hline $\mathrm{R}^{2}$ & 0.123 & 0.163 & 0.228 & 0.235 \\
\hline Adjusted $\mathrm{R}^{2}$ & 0.116 & 0.155 & 0.220 & 0.225 \\
\hline $\mathrm{F}$ & 18.460 & 19.255 & 29.151 & 24.158 \\
\hline sig & 0.000 & 0.000 & 0.000 & 0.000 \\
\hline
\end{tabular}

For Equation (1): Dependent Variable = Budget Slack. For Equation (2): Dependent Variable = Emotional exhaustion. For Equation (3): Dependent Variable = Budget Slack. For Equation (4): Dependent Variable = Budget Slack. 


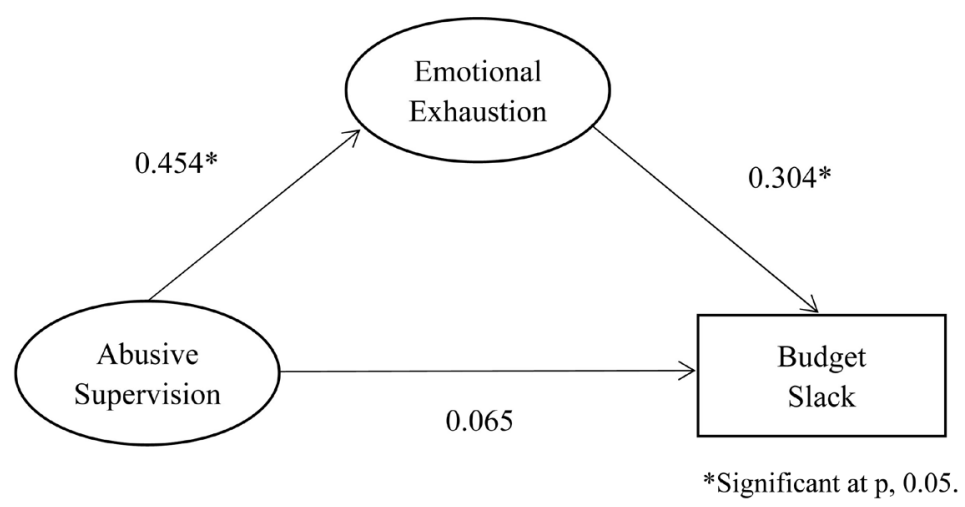

Figure 1. Results of tests of mediation.

\section{Discussion and Conclusions}

In the study of abusive supervision, it is usually connected with count-produce behavior (Ding et al., 2016) and workplace deviation behavior (Tepper, 2000). Restraining the budget slack has always been one of important issue in organizations. Most of the relevant literatures study how to restrain budget slack from the perspective of agency theory such as budget participation (Huang, 2012), information asymmetry (Chow et al., 1988), budget-based contract (Schif \& Lewin, 1970), variance investigation (Webb, 2002) and so on. However, the problem of budget slack is not only the agent problem, but also the violation of social norms and deviant behavior (Deng et al., 2014). To our knowledge, abusive supervision has not been extended into the budget environment. Thus, our results contribute and innovate to research that introduces the abusive supervision into the budget environment and complements other negative behavior induced by abusive supervision to explore the influence path of abusive supervision on budget slack.

There are several limitations. First, the population selected in this paper is the employee of the production department. Second, the individual differences are not taken into account in the study of abusive supervision perceived by subordinates and budget slack.

Future research is needed to take into account individual differences, such as the degree of individual dependence on the organization, and the final budget slack behavior will be different. For example, according to the power/dependence theory, the impact of abusive supervision on budget slack is also affected by the degree of individual dependence on the organization. The study has shown that abusive supervision is more strongly associated with subordinates' workplace deviance behavior when subordinates' intention to quit is higher (Tepper et al., 2009). Therefore, the variables of individual dependence on organization should be taken into account in future research.

\section{Conflicts of Interest}

The authors declare no conflicts of interest regarding the publication of this paper. 


\section{References}

Aryee, S., Sun, L. Y., \& Chen, Z. X. G. (2008). Abusive Supervision and Contextual Performance: The Mediating Role of Emotional Exhaustion and the Moderating Role of Work Unit Structure. Management and Organization Review, 4, 393-411. https://doi.org/10.1111/j.1740-8784.2008.00118.x

Ashforth, B. E. (1997). Petty Tyranny in Organizations: A Preliminary Examination of Antecedents and Consequences. Canadian Journal of Administrative Sciences, 14, 126-140. https://doi.org/10.1111/j.1936-4490.1997.tb00124.x

Baron, \& Kenny. (1986). The Moderator-Mediator Variable Distinction in Social Psychological Research: Conceptual, Strategic, and Statistical Considerations. Journal of Personality and Social Psychology, 51, 1173-1182.

https://doi.org/10.1037/0022-3514.51.6.1173

Bourageois. L. J. (1981). On the Measurement of Organizational Slack. The Academy of Management Review, 6, 29-39. https://doi.org/10.5465/amr.1981.4287985

Cao, Y.K., Li, Z. C., \& Zhan, X, J. (2015). Study on the Effects of Abusive Supervision on Emotional Exhaustion in Subordinates: The Role of Emotional Labor and Co-Worker Support. CUHK Management Research, 10, 39-57.

Chi, S. C. S., \& Liang, S. G. (2013). When Do Subordinates' Emotion-Regulation Strategies Matter? Abusive Supervision, Subordinates' Emotional Exhaustion, and Work Withdrawal. The Leadership Quarterly, 24, 125-137.

https://doi.org/10.1016/j.leaqua.2012.08.006

Chow, C. W., Cooper, J. C., \& Waller, W. S. (1988). Participative Budgeting: Effects of a Truth-Inducing Pay Scheme and Information Asymmetry on Slack and Performance. The Accounting Review, 63, 111-122.

Covaleski, M. A., Evans III, J. H., \& Luft, J. L. (2003). Budgeting Research: Three Theoretical Perspectives and Criteria for Selective Integration. Journal of Management Accounting Research, 15, 3-49. https://doi.org/10.2308/jmar.2003.15.1.3

Deng, D. Q., Liu, H. T., Xie, H., \& Miao, X. W. (2014). The Role of External Control and Self-control in Suppressing Budget Slack: An Experimental Study Based on Difference Investigation and Moral Cognition. Accounting Research, No. 4, 49-57+96.

Ding, Y. L., Yang, Y., \& Gao, J. S. (2016). Study on the Effect of Localization and Abusive Supervision and Organizational Psychological Safety on Staff Silence. Forum on Statistics and Information, 31, 92-97.

Dunk, A. S., \& Nouri, H. (1998). Antecedents of Budgetary Slack: A Literature Review and Synthesis. Journal of Accounting Literature, 17, 72-96.

Gao, Y., \& Peng, S. B. (2009). Budget Slack: An Investigation Based on Information Asymmetric Theory. Journal of Beijing Business University, No. 3, 82-87.

Golparvar, M. (2015). Unconventional Functions of Deviant Behaviors in the Relationship between Job Stress and Emotional Exhaustion: Three Study Findings. Current Psychology, 35, 269-284. https://doi.org/10.1007/s12144-014-9292-8

Harvey, P., Stoner, J., Hochwarter, W., \& Kacmar, C. (2007). Coping with Abusive Supervision: The Neutralizing Effects of Ingratiation and Positive Effect on Negative Employee Outcomes. The Leadership Quarterly, 18, 264-280. https://doi.org/10.1016/j.leaqua.2007.03.008

Hobfoll, S. E., Freedy, J., Lane, C., \& Geller, P. (1990). Conservation of Social Resources: Social Support Resource Theory. Journal of Social \& Personal Relationships, 7, 465-478. https://doi.org/10.1177\%2F0265407590074004 
Huang, D. J., Li, J., \& Li, H. (2017). Effects of Abusive Supervision on the Deviant Behavior of Township Civil Servants: Mediating Role of the Violation of Psychological Contract. Soft Science, 31, 87-91.

Huang, Z. G. (2012). An Empirical Analysis of the Causes of Departmental Budget Slack Based on Budget Rigidity and Budget Participation: Based on the Survey Questionnaire of Administrative Institutions in Xinjiang. Administrative Assets and Finance, No. 6, 64-66.

Kim, S., Hwang, J., \& Lee, D. (2008). Prefrontal Coding of Temporally Discounted Values During Intertemporal Choice. Neuron, 59, 161-172.

https://doi.org/10.1016/j.neuron.2008.05.010

Kimberly, J. R. (1976). Organizational Size and the Structuralist Perspective: A Review, Critique, and Proposal. Administrative Science Quarterly, 21, 571-597. https://doi.org/10.2307/2391717

Kouchaki, M., \& Desai, S. D. (2015). Anxious, Threatened, and Also Unethical: How Anxiety Makes Individuals Feel Threatened and Commit Unethical Acts. Journal of Applied Psychology, 100, 360-375. https://doi.apa.org/doi/10.1037/a0037796

Kren, L. (1992). Budgetary Participation and Managerial Performance: The Impact of Information and Environmental Volatility. Accounting Review, 67, 511-526.

Lawrence, E. R., \& Michele, K. K. (2017). Exploring the Impact of Job Insecurity on Employees Unethical Behavior. Business Ethics Quarterly, 27, 39-70. https://doi.org/10.1017/beq.2016.58

Li, Y. X., \& Li, Y. M. (2006). Preliminary Discussion on the Evaluation Standard of Job Burnout. Psychological Science, 29, 148-150.

Libby, T., \& Linsay, R. M. (2010). Beyond Budgeting or Budgeting Reconsidered? A Survey of North-American Budgeting Practice. Management Accounting Research, 21, 56-75. https://doi.org/10.1016/j.mar.2009.10.003

Libby. T. (1999). The Influence of Voice and Explanation on Performance in a Participative Budgeting Setting. Accounting, Organizations and Society, 24, 125-137. https://doi.org/10.1016/S0361-3682(98)00043-9

Little, H. T., Magner, N. R., \& Welker, R. B. (2002). The Fairness of Formal Budgetary Procedures and Their Enactment Relationships with Managers Behavior. Group \& Organization Management, 166, 209-225. https://doi.org/10.1177\%2F10501102027002003

Ma, Y. Q., Xi, M., Xu, Q., \& Zhao, S. M. (2017). Study on the Mechanism of Abusive supervision on Subordinate Anti-Production Behavior Based on Social Cognitive Theory. Management Journal, 14, 1153-1161.

Mao, H. T., \& Zhu, B. (2009). A Review of the Research on the Behavioral Motivation of Budget Slack Based on Four Theoretical Perspectives. Scientific Decision-Making, No. 11, 82-94.

Maslach, C., Jackson, S. E., Leiter, M. P., Schaufeli, W. B. I., \& Schwab, R. L. (1986). Maslach Burnout Inventory. Consulting Psychologists Press, No. 2.

Mazar, N., Amir, O., \& Ariely, D. (2008). The Dishonesty of Hones People: A Theory of Self-Concept Maintenance. Journal of Marketing Research, 45, 633-644. https://doi.org/10.1509\%2Fjmkr.45.6.633

McDaniel, C. Jr., \& Gates, R. (2015). Marketing Research Essentials (9th Edition). John Wiley \& Sons.

Mitchell, M. S., Bear, M. D., Ambrose, M. L., Folger, R., \& Palmer, N. F. (2018). Cheating under Pressure: A Self-Protection Model of Workplace Cheating Behavior. Journal of 
Applied Psychology, 103, 54-73. https://doi.apa.org/doi/10.1037/apl0000254

Onsi, M. (1973). Factor Analysis of Behavioral Variables Affecting Budgetary Slack. The Accounting Review, 48, 535-548.

Rogers, R. W. (1975). A Protection Motivation Theory of Fear Appeals and Attitude Change1. Journal of Psychology Interdisciplinary \& Applied, 91, 93-114. https://doi.org/10.1080/00223980.1975.9915803

Schatzberg, J. W., \& Stevens, D. E. (2008). Public and Private Forms of Opportunism within the Organization: A Joint Examination of Budget and Effort Behavior. Journal of Management Accounting Research, 20, 59-81.

Schif, F. M., \& Lewin, A. Y. (1970). The Impact of People on Budgets. Accounting Review, 45, 259-268.

Stevens, D. E. (2002). The Effects of Reputation and Ethics on Budgetary Slack. Journal of Management Accounting Research, 14, 153-171.

https://doi.org/10.2308/jmar.2002.14.1.153

Subramaniam, N., \& Mia, L. (2003). A Note on Work-Related Values, Budget Emphasis and Managers' Organisational Commitment. Management Accounting Research, 14, 389-408. https://doi.org/10.1016/j.mar.2003.07.001

Sun, J. S. (2019). The Effect of Abusive Supervision on Employee Cheating Behavior.

Tepper, B. J., Carr, J. C., \& Breaux, D. M. (2009). Abusive Supervision, Intentions to Quit, and Employees' Workplace Deviance: A Power/Dependence Analysis. Organizational Behavior and Human Decision Processes, 109, 156-167. https://doi.org/10.1016/j.obhdp.2009.03.004

Tepper, B. J., Duffy, M. K., \& Shaw, J. D. (2001). Personality Moderators of the Relationship between Abusive Supervision and Subordinates' Resistance. Journal of Applied Psychology, 86, 974-983. https://doi.apa.org/doi/10.1037/0021-9010.86.5.974

Tepper, B. J. (2000). Consequence of Abusive Supervision. Academy of Management Journal, 43, 178-190.

Tepper, B. J. (2007). Abusive Supervision in Work Organizations: Review, Synthesis, and Research Agenda. Journal of Management, 33, 261-289. https://doi.org/10.1177\%2F0149206307300812

Thau, S., \& Mitchell, M. S. (2010). Self-Gain or Self-Regulation Impairment? Tests of Competing Explanations of the Supervisor Abuse and Employee Deviance Relationship through Perceptions of Distributive Justice. Journal of Applied Psychology, 95, 1009-1031. https://doi.apa.org/doi/10.1037/a0020540

Webb, R. A. (2002). The Impact of Reputation and Variance Investigations on the Creation of Budget Slack. Accounting Organization and Society, 27, 361-378. https://doi.org/10.1016/S0361-3682(01)00034-4

Whitman, M. V, Halbesleben, J. R. B., \& Oscar Holmes, I. V. (2012). Abusive Supervision and Feedback Avoidance: The Mediating Role of Emotional Exhaustion. Journal of Organizational Behavior, 35, 38-53. https://doi.org/10.1002/job.1852

Yu, Z. B., Yuan, G. H., \& Liu, G. Y. (2004). Research on the Framework of Budget Management System of Group. Accounting Research, No. 8, 21-28.

Zhang, H. P., Kwan, H. K., Zhang, X. M., \& Wu, L. Z. (2014). High Core Self-Evaluators Maintain Creativity: A Motivational Model of Abusive Supervision. Journal of Management, 40, 1151-1174. https://doi.org/10.1177\%2F0149206312460681

Zhang, C. M., Zhuo, Y., \& Dong, W. (2004). Experimental Study on Budget SlackBehavior. Journal of Management Science, No. 3, 46-53.

Zhang, Li, Lin, Y. C., \& Zhang, L. (2014). Effects of Job Insecurity on Emotional Exhaus- 
tion: Moderating of Social Support. Scientific Research Management, 35, 91-98.

Zhang, X. Z., \& Zhai, Y. L. (2009). Research on Compensation Contract and Budget Slack Based on Risk Preference. Research on Financial Issues, 6, 53-60. 